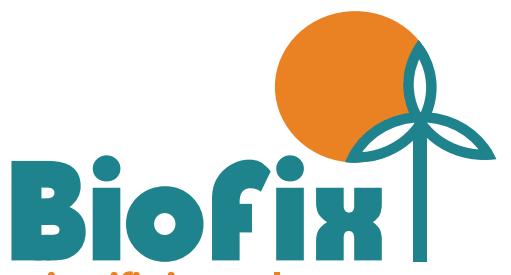

scientific journal

v. 2 n. 12017

Recebido em 08/02/2017

Aceito em 09/03/2017

Publicado em 20/04/2017

DOI: dx.doi.org/10.5380/biofix.v2i1.50488

\section{MUDANÇAS SOCIOECONÔMICAS E NA GESTÃO DE RESÍDUOS APÓS IMPLEMENTAÇÃO DE UMA COOPERATIVA DE RECICLAGEM}

\author{
SOCIOECONOMICAL AND WASTE MANAGEMENT CHANGES AFTER \\ IMPLEMENTATION OF A RECYCLING COOPERATIVE
}

\author{
Bárbara Aliot da Costa Ravanello ${ }^{1}$ \\ Greyce Charllyne Benedet Maas²
}

Universidade Federal do Paraná, Curitiba, Paraná, Brasil barbaraliot@hotmail.com ${ }^{1}$ \&greyce.maas@gmail.com ${ }^{2}$

\section{RESUMO}

Foram analisadas as mudanças socioeconômicas com os antigos catadores e atuais cooperados e as mudanças na coleta e destinação dos resíduos sólidos urbanos após a implementação de uma cooperativa de reciclagem em União da Vitória - PR. Foram entrevistados $70 \%$ dos cooperados e analisados os dados da Prefeitura Municipal e da Secretaria do Meio Ambiente referentes à quantificação dos resíduos. O percentual de resíduos coletados encaminhados para usinas de separação de recicláveis aumentou de $2 \%$ para $16 \%$. Dos resíduos recicláveis coletados, $71 \%$ são enviados para reciclagem e $29 \%$ para aterro sanitário. A média per capita de resíduos recicláveis recuperados é de 25,56 kg.hab ${ }^{-1}$.ano-1, superior à média nacional e da região Sul. A cooperativa proporcionou melhoria na qualidade de vida dos cooperados, relacionada a formalização do trabalho, melhoria dos salários, saúde e segurança, além de influenciar positivamente na satisfação com a atividade desenvolvida.

PALAVRAS-CHAVE: Catadores, Coleta seletiva, Lixo, Perfil socioeconômico, Recicláveis.
Socioeconomic changes of former street pickers and current cooperative members and changes in collection and disposal of municipal solid waste in the municipality União da Vitória - PR after the implementation of a recycling cooperative. Seventy percent of the members of the cooperative were interviewed and the data regarding the quantification of waste coming from the Department of the Environment of the municipality were analyzed. The percentage of recyclable waste collected sent to separation plants increased from $2 \%$ to $16 \%$. Seventy one percent of the recyclable waste was sent for recycling and $29 \%$ for landfill. The average per capita yield of recyclable waste recovered is $25.56 \mathrm{~kg}$.inhabitant $^{-1}$.year ${ }^{-1}$, higher than the national and South region averages. The cooperative provided improvement in the quality of life of its members, due to job formalization, better wages, improved health and safety, as well as satisfaction with the activity carried out.

KEYWORDS: Waste pickers, Selective disposal, Garbage, Socioeconomic profile, Recyclable.

\section{ABSTRACT}




\section{INTRODUÇÃO}

Vários autores têm se dedicado ao estudo da problemática dos resíduos sólidos urbanos - RSU (SIQUEIRA; SOARES, 2009; SOBARZO; MARIN, 2010; GÓES, 2011; JACOBI; BESEN, 2011; GOMES et al., 2012; HEMPE; NOGUEIRA, 2012; GONÇALVES et al., 2013; DEUS et al., 2015, FREITAS, 2015; FERREIRA SILVA et al., 2016), dado que se trata de um tema de fundamental importância para a gestão de cidades e do meio ambiente urbano. 0 volume de RSU gerado no Brasil anualmente é imenso, conforme atestam os relatórios das entidades representativas. Em 2013, por exemplo, a geração total foi de 76.387.200 $\mathrm{t}$, o que representa um aumento de 4,1\% em relação ao ano anterior (ABRELPE, 2014). O RSU produzido nas cidades é cada vez mais constituído de elementos de difícil degradação, no entanto, por meio de processos de reciclagem, os impactos ambientais e sociais desses resíduos podem ser minimizados (SIQUEIRA; MORAES, 2009; DE PAULA et al., 2010; GODECKE; WALERKO, 2015).

A Política Nacional de Resíduos Sólidos (PNRS) veio auxiliar na busca pelo desenvolvimento sustentável, o qual está consubstanciado na harmonia entre o setor econômico, ambiental e social (LINHARES MAIA et al., 2014). A PNRS visa a prevenção e a redução da geração de resíduos, tendo como proposta um conjunto de instrumentos para propiciar o aumento da reciclagem e da reutilização dos resíduos. Ela visa também a integração dos catadores de materiais recicláveis nas ações que envolvam a responsabilidade compartilhada pelo ciclo de vida dos produtos, sendo o incentivo à criação e ao desenvolvimento de cooperativas ou outras formas de associação de catadores de material reciclável um dos instrumentos de sua política (BRASIL, 2010).

De acordo com o Decreto 7.404/2010, que regulamenta a Lei Federal 12.305/2010, o sistema de coleta seletiva de resíduos sólidos deve priorizar a participação de cooperativas ou outras formas de associação de catadores de materiais recicláveis, sendo constituídas por pessoas físicas de baixa renda, assim como os planos municipais de gestão integrada de resíduos sólidos devem definir programas e ações para a participação das cooperativas. Além disso, a União deve criar, por meio de regulamento específico, programa com a finalidade de melhorar as condições de trabalho e as oportunidades de inclusão social e econômica (BRASIL, 2010).

A coleta seletiva foi definida na Lei Federal $\mathrm{n}$ ㅇ 12.305/10 como a coleta de resíduos sólidos previamente separados de acordo com a sua constituição e composição, devendo ser implementada por municípios como forma de encaminhar as ações destinadas ao atendimento do princípio da hierarquia na gestão de resíduos (BRASIL, 2010). O Ministério das Cidades lançou em 2015 o Diagnóstico do Manejo de Resíduos Sólidos Urbanos, o qual apurou que, em 2013, a coleta seletiva era praticada em 1.161 dos 3.572 municípios participantes $(32,5 \%)$, constatando-se que ainda não é uma realidade em grande parte dos municípios brasileiros.

Dentre os benefícios que resultam da coleta de material reciclável, além da geração de renda para os trabalhadores envolvidos, pode-se citar a contribuição à saúde pública e ao sistema de saneamento; o fornecimento de material reciclável de baixo custo à indústria; a redução nos gastos municipais e a contribuição à sustentabilidade do meio ambiente, tanto pela diminuição de matéria-prima primária utilizada, que conserva recursos e energia, como pela diminuição da necessidade de terrenos a serem utilizados como lixões e aterros sanitários (DE PAULA et al., 2010).

A formação de cooperativas de reciclagem no Brasil tem sido objeto de pesquisas, as quais mostram a importância da atividade para mitigar o impacto ambiental da destinação dos resíduos sólidos urbanos. Essas cooperativas contribuem com a extensão da vida útil dos materiais e embalagens por meio da coleta, separação e fornecimento de matéria-prima secundária para a indústria. A cooperativa também é uma oportunidade de resgate da dignidade humana do catador, como também de desenvolvimento e ajuda mútua. A catação dos resíduos recicláveis no Brasil tem como marca a presença maciça de trabalhadores informais e uma participação pouco significativa dos poderes públicos em programas de coleta seletiva, sendo as organizações uma saída da situação de exploração (PINHEL et al., 2013).

Nesse contexto, no município de União da Vitória, foi criado em 2013 o projeto Ecocidade de uma iniciativa do Poder Público Municipal, com objetivos que envolviam a criação de uma cooperativa de catadores; criação de uma usina de triagem de resíduos recicláveis; implantação de um sistema de coleta seletiva e promoção da educação ambiental, visando orientar a população sobre a maneira adequada de separar e acondicionar os resíduos (PREFEITURA MUNICIPAL DE UNIÃO DA VITÓRIA, 2015). Diante do exposto, o objetivo deste estudo foi analisar as mudanças na gestão dos resíduos sólidos e nos aspectos socioeconômicos relacionados aos cooperados oriundas 
da implementação do projeto Ecocidade e da Cooperativa de Reciclagem - COOPERTRAGE em União da Vitória - PR.

\section{MATERIAL E MÉTODOS}

O estudo foi realizado no município de União da Vitória, o qual está situado no extremo Sul do estado do Paraná e pertencente a microrregião do Médio Iguaçu. Segundo dados do Instituto Brasileiro de Geografia e Estatística (IBGE) de 2010, a cidade conta com 52.735 habitantes e sua área total é de $719,998 \mathrm{~km} 2$. Por estar separada da cidade de Porto União, estado de Santa Catarina, apenas por uma linha férrea, forma um único núcleo urbano de aproximadamente 86.000 habitantes. Além disso, 46.305 pessoas são alfabetizadas em União da Vitória, valor que corresponde a $87,8 \%$ da população. 0 município conta com 32 estabelecimentos de saúde e o Índice de Desenvolvimento Humano Municipal (IDHM) é de 0,740 (IBGE, 2010).

A COOPERTRAGE - Cooperativa de Trabalho dos Agentes Ecológicos de União da Vitória, foi criada no ano de 2013 a partir do projeto Ecocidade e está localizada no bairro São Sebastião, pertencente ao município de União da Vitória, em uma antiga usina de calcário de 1.750 m2. A cooperativa conta com balança rodoviária com capacidade para 80 toneladas, secretaria, vestiários, banheiros e chuveiros, refeitório e cozinha, além de um barracão com duas esteiras para a separação dos materiais e quatro prensas para compactação dos resíduos.

A cooperativa iniciou suas atividades com 25 cooperados em fevereiro de 2014, com a coleta de recicláveis sendo realizada apenas no Distrito de São Cristóvão. Após reuniões e palestras para informar a população sobre o projeto, em outubro de 2014 a coleta seletiva foi expandida para o restante do município, atendendo $100 \%$ da população urbana. Atualmente a COOPERTRAGE possui 51 cooperados, divididos em setores dentre as seguintes funções: coletor, separador, prensador e administrativo. Outros cargos são contratados e não cooperados, com as funções de limpeza, gerência e secretaria.

São recebidos materiais como papel, papelão, sacolas plásticas, materiais em PVC (policloreto de vinila) e PET (polietileno tereftalato), alumínio, cobre, resíduo eletrônico, vidro, isopor, ferro, metal e madeira. Todos os materiais são separados nas esteiras e prensados para posterior comercialização. Os rejeitos recebidos junto ao material são separados em caçamba e encaminhados para o aterro sanitário do município. O funcionamento da cooperativa é de segunda a sexta-feira em horário comercial e aos sábados a cada 15 dias. A coleta é realizada porta a porta todos os dias da semana, conforme os bairros, exceto no domingo, em que não há expediente.

Com o repasse mensal de recurso oriundo do Contrato de Prestação de Serviço com a Prefeitura Municipal de União da Vitória, são fornecidos alimentação e transporte aos cooperados, além dos pagamentos dos contratados e despesas com energia elétrica, água, entre outros. O lucro proveniente da venda do material é dividido entre os cooperados. O monitoramento e supervisão da cooperativa é realizado pela SEMMA - Secretaria Municipal do Meio Ambiente (PREFEITURA MUNICIPAL DE UNIÃO DA VITÓRIA, 2015).

\section{Método de análise}

Para avaliar a influência da cooperativa em aspectos socioeconômicos relacionados aos cooperados, foi desenvolvido um questionário abordando dados pessoais, como idade, sexo, estado civil, escolaridade, entre outros, bem como aspectos relacionados ao trabalho, como: tempo na cooperativa, ganho, mudança na qualidade de vida, satisfação do trabalho realizado, etc.

O questionário foi aplicado em 36 cooperados de variados setores por meio de entrevista individual. Optouse por utilizar preferencialmente questões fechadas para melhor quantificação dos resultados. Porém, foi adicionado o item "Observação", a fim de complementar as informações fornecidas pelos cooperados. Algumas questões, como idade e número de filho, foram abertas para posterior agrupamento em classes. Foram realizadas diversas visitas à cooperativa, a fim de atingir maior número possível de entrevistas.

Os dados da quantidade coletada de resíduos anteriormente a existência da cooperativa foram obtidos com a Secretaria Municipal do Meio Ambiente, a qual possui os documentos referentes à gestão ambiental de União da Vitória. A coleta dos resíduos no município era realizada por uma empresa privada contratada mediante processo licitatório, que encaminhava os resíduos recicláveis à antiga associação de catadores. A coleta era realizada de porta em porta com dois caminhões distintos, um caminhão para os recicláveis e outro para os não recicláveis. Atualmente, a coleta do resíduo não reciclável é realizada por essa mesma empresa e a coleta do resíduo reciclável é realizada pela cooperativa.

A empresa contratada não realizava pesagens regulares dos resíduos. Dessa forma, a estimativa mensal 
da quantidade de resíduos recicláveis e não recicláveis coletados antes da implementação da cooperativa se baseou nos resultados das pesagens realizadas durante 0 período de uma semana no mês de março de 2012, sendo que a partir desse resultado estimou-se a quantidade mensal coletada. Não há registros da quantidade de resíduos recicláveis comercializada pela antiga Associação de Catadores. Segundo informações dos associados, as perdas em relação à quantidade de material coletada eram maiores, devido possivelmente a falta de um programa de educação ambiental que orientasse os moradores com relação ao descarte adequado, incluindo, por exemplo, a lavagem de embalagens como potes de margarina e iogurte, embalagens de refrigerantes, entre outros.

Com o início do projeto Ecocidade foram realizadas diversas ações de educação ambiental com o objetivo de orientar os moradores a realizar o descarte de maneira correta. Foram realizadas reuniões nos bairros; parcerias com outras secretarias; divulgação em escolas, associações, empresas, igrejas, etc.; divulgação em meios de comunicação; criação de folder e ímã de geladeira; divulgação porta a porta e também criação de gibi visando a divulgação no ensino fundamental (PREFEITURA MUNICIPAL DE UNIÃO DA VITÓRIA, 2015).

Foram também analisados os relatórios da cooperativa com os registros das pesagens mensais dos resíduos sólidos coletados e dos resíduos efetivamente encaminhados para indústrias de reciclagem dos meses de dezembro de 2014 a junho de 2015. Desde o primeiro mês em que a cooperativa iniciou suas atividades, as pesagens dos materiais recicláveis são realizadas diariamente assim que o caminhão de coleta chega na cooperativa. Com a quantidade de resíduos coletada mensalmente pela cooperativa e a quantidade efetivamente comercializada foi possível estimar o percentual de perdas de material, que são encaminhados ao aterro sanitário do município.

\section{RESULTADOS E DISCUSSÃO}

O total mensal de material enviado para a reciclagem passou de 16 toneladas (realizado por uma empresa do munícipio somente na área Central da cidade) para 80 toneladas somente no Distrito de São Cristóvão, mostrando adesão da população ao projeto. Após ampliação do projeto para todos os bairros do município, o total dos materiais recicláveis chegou a 150 toneladas/mês. Sendo assim, após a introdução da cooperativa, houve um aumento de $937,5 \%$ na quantidade de material reciclável coletado (PREFEITURA MUNICIPAL DE UNIÃO DA VITÓRIA, 2015).

Dessa maneira, antes da implementação do projeto estima-se que apenas $2 \%$ do total de resíduos coletados eram encaminhados para reciclagem. Após o início do projeto esse percentual aumentou para 16\%. Em 2008, a quantidade diária de resíduos sólidos encaminhados para triagem para a reciclagem no Brasil era de $1,4 \%$, enquanto $58,3 \%$ dos resíduos eram encaminhados para aterro sanitário (IPEA, 2013).

As 16 toneladas recolhidas anteriormente eram encaminhadas para uma antiga associação de catadores do município. Segundo informações da Prefeitura Municipal de União da Vitória, a antiga associação não recebia muito apoio do poder público, sendo que os associados migraram para a nova cooperativa. Por outro lado, após a implementação da cooperativa, a quantidade média de resíduo não reciclável encaminhada para o aterro do município, se manteve a mesma da coleta realizada antes da implementação do projeto (Figura 1).

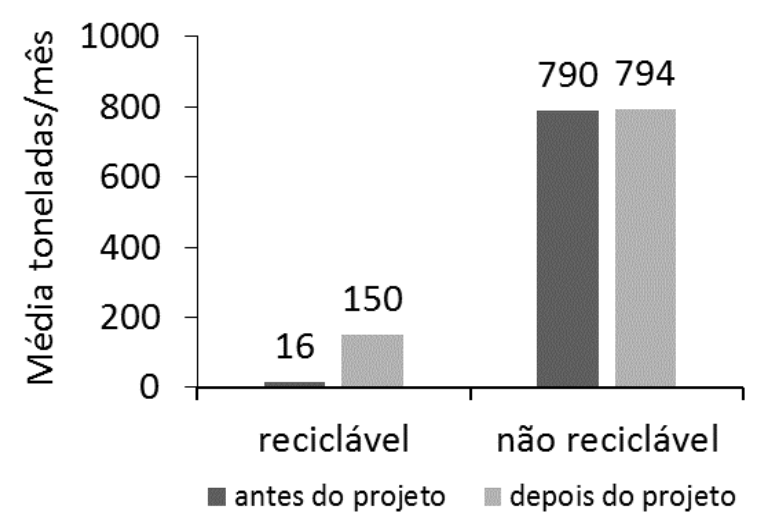

Figura 1. Comparação entre a quantidade média mensal de resíduos coletados no município de União da Vitória antes e depois do projeto Ecocidade.

A partir dos dados da pesagem realizada antes da implementação da cooperativa, em março de 2012, foi estimado o valor de 790 t.mês ${ }^{-1}$ de resíduos não recicláveis coletados. Analisando-se os relatórios do Contrato de Prestação de Serviço da empresa que faz a coleta dos resíduos não recicláveis em União da Vitória, atualmente coleta-se em média 794 toneladas por mês de resíduo orgânico no município. Esse valor refere-se à média da coleta dos meses de dezembro de 2014 a junho de 2015.

Esperava-se que o aumento na quantidade de resíduos recicláveis coletados com a implementação do projeto refletisse em uma diminuição na quantidade de resíduos classificados como não recicláveis enviados ao aterro 
sanitário. Entretanto, deve-se considerar que a pesagem dos resíduos coletados antes da implementação da cooperativa foi realizada em apenas uma semana do mês de março de 2012, o que pode não ser representativo para estimar a média mensal. A geração de resíduos, por diversos motivos, pode variar ao longo dos meses, assim, para obter uma quantificação mais precisa os resíduos não recicláveis deveriam ter sido pesados em diferentes meses.

Também é necessário considerar que no período de 2012 a 2015 pode ter ocorrido um aumento no poder aquisitivo da população com consequente aumento no consumo e geração de resíduos. Segundo Campos (2012) os resíduos sólidos podem ser considerados como importante indicador socioeconômico, tanto por sua quantidade como também pela sua caracterização, assim, fatores econômicos como crise ou apogeu refletem diretamente no consumo de bens duráveis e não duráveis, na alimentação e na consequente geração de resíduos sólidos. Outros autores também relacionam a geração e destinação de resíduos sólidos a indicadores socioeconômicos (GOUVEIA, 2012; DIAS et al., 2012; COSTA et al., 2013; RAMOS, 2013; BRAZ et al., 2014).

De acordo com a Abrelpe (2014), a geração total de RSU no Brasil aumentou 4,1\% de 2012 para 2013. No estado do Paraná, a destinação final no aterro sanitário de RSU passou de 5.433 toneladas/dia em 2012 para 5.686 toneladas/dia em 2013. Na Figura 2 consta a variação mensal na coleta de resíduos não recicláveis no município.

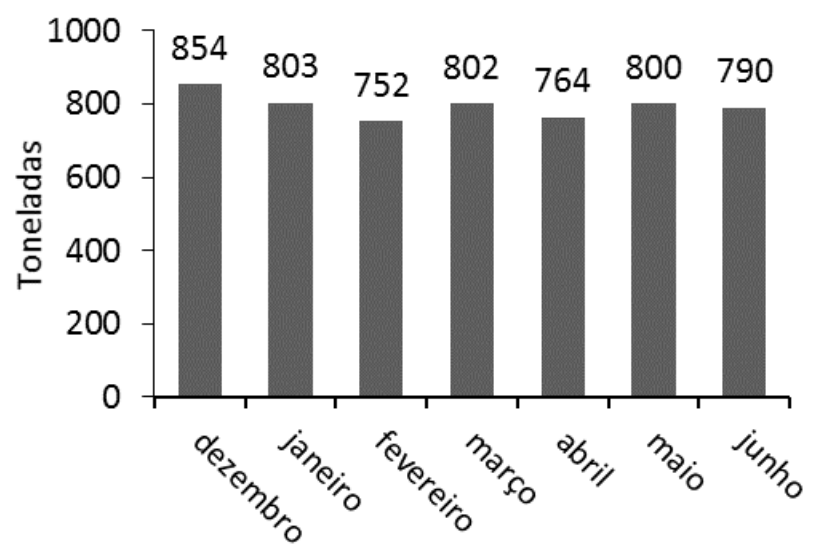

Figura 2. Variação da quantidade de resíduos não recicláveis coletados no município de União da Vitória entre dezembro de 2014 e junho de 2015.

Observa-se que a variação entre o mês com maior e menor quantidade de resíduos não recicláveis coletada foi de 102 toneladas. O mês com maior quantidade de resíduos não recicláveis coletada foi dezembro, possivelmente devido a se tratar de uma época de festas de fim de ano, na qual famílias e restaurantes preparam grandes quantidades de alimentos gerando sobras.

Dos resíduos recicláveis que chegam à cooperativa, nem todo o material é efetivamente comercializado gerando rejeitos que são enviados ao aterro sanitário do município, conforme pode ser observado na Figura 3. Ocorre em média uma perda de $29 \%$ dos resíduos encaminhados a cooperativa. Segundo informações dos gestores da cooperativa, esse material é composto principalmente por resíduos recicláveis que não foram lavados e resíduos não recicláveis dispostos inadequadamente nos sacos de resíduos recicláveis.

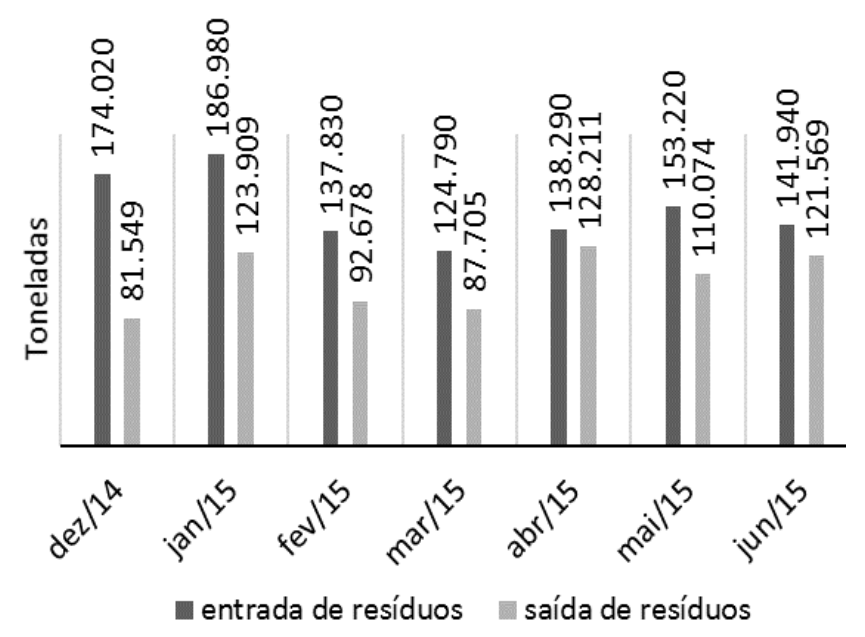

Figura 3. Relação entre a quantidade de resíduos que chega à Cooperativa COOPERTRAGE e que sai (venda) em diferentes meses do ano.

Segundo o Ministério das Cidades (2015) a massa per capita de resíduos recicláveis recuperados para a faixa populacional de 30.001 a 100.000 habitantes é de 12,4 kg.hab ${ }^{-1}$.ano-1 ${ }^{-1}$ enquanto a média do país em 2013 foi de 6,7 kg.hab ${ }^{-1}$.ano-1 ${ }^{-1}$ Também de acordo com o Ministério das Cidades (2015) a massa recuperada de materiais recicláveis segundo a região geográfica indica $8,5 \mathrm{~kg}$.hab ${ }^{1}$.ano-1 para o Sul do país. Em União da Vitória, de acordo com o CENSO 2010, a população urbana corresponde a 49.983 pessoas (IBGE, 2010). Dessa maneira, descontados os $29 \%$ de rejeitos nos resíduos coletados, a massa per capita de resíduos recicláveis recuperados no município, é de 2,13 kg.hab ${ }^{-1}$.mês ${ }^{-1}$ ou 25,56 kg.hab ${ }^{-1}$.ano ${ }^{-1}$, muito superior à média do país e da região Sul.

Dos 51 cooperados foram obtidas 36 entrevistas, sendo 16 mulheres e 20 homens. Outras 4 entrevistas foram realizadas, porém, foram desconsideradas visando não comprometer os dados gerados, devido ao mal entendimento das questões, esquecimentos e falta de 
compreensão por parte dos entrevistados. Outros 11 cooperados optaram por não responder ao questionário, devido à timidez ou receio da divulgação das respostas. Foram questionados separadores, coletores, prensadores e outros cargos como, por exemplo, diretor e conselheiro fiscal.

Carmo (2009) realizou um trabalho em três cooperativas do Rio de Janeiro e concluiu que há alta rotatividade de cooperados em duas das três cooperativas observadas, mostrando a ausência de sentimento de filiação (ou pertença) e de identificação com o trabalho. Entretanto, dos entrevistados da COOPERTRAGE, 78\% estão na cooperativa a mais de 6 meses e $28 \%$ estão desde o início de seu funcionamento, indicando vínculo ao local e trabalho realizado. Dos 36 entrevistados, 3 eram idosos (acima de 65 anos) e o restante adultos, sendo que $50 \%$ dos entrevistados possuem entre 30 e 50 anos. Adultos jovens (entre 18 e 30 anos) perfizeram 42\% dos entrevistados.

O IPEA (2013) desenvolveu um quadro síntese sobre a situação social dos catadores de material reciclável no Brasil a partir de dados do censo demográfico do IBGE e do PNAD. Nesse quadro, a média de idade dos catadores no Brasil é de 39,4 anos e no Sul de 38,9 anos. Na COOPERTRAGE a média da idade dos cooperados entrevistados foi similar, sendo 39,35 anos. Entre os cooperados, foram observados todos os níveis de escolaridade exceto Ensino Superior. Em estudos correlatos (ALMEIDA et al., 2009; FREITAS; FERREIRA, 2015; TEIXEIRA, 2015), observou-se maior frequência de catadores na fase adulta.

Segundo o IBGE, a média nacional de analfabetos corresponde a $8 \%$ da população brasileira (IBGE, 2010). No Paraná esse valor é ainda menor, em 2009 os analfabetos compunham $6,7 \%$ da população do estado. Sendo assim, na cooperativa a quantidade de analfabetos entrevistados (19\%) é superior à média nacional e estadual sendo também maior que a taxa de analfabetismo dos catadores da região Sul que é de $15,5 \%$, e semelhante à dos catadores no Brasil correspondente a 20,5\% (IPEA, 2013). Ainda com relação à escolaridade, percebe-se que essa é uma característica marcante entre catadores e catadoras de outros estados do país (CAVALCANTE et al., 2012). Em Minas Gerais, Jesus et al. (2012) encontraram que $75 \%$ dos catadores são analfabetos ou possuem o ensino fundamental incompleto.

Anteriormente à cooperativa, 19 cooperados eram catadores na rua, 7 estavam desempregados e 10 executavam outros serviços como jardineiro, doméstica, empacotador de supermercado, servente, entre outros. Segundo Cavalcante et al. (2012) parte desses trabalhadores de cooperativas é oriunda da população desempregada que, atingida pela condição social e baixa escolaridade, não encontram espaço no mercado formal de trabalho. O motivo pelo qual os trabalhadores migraram para a cooperativa é exposto na Figura 4 a seguir.

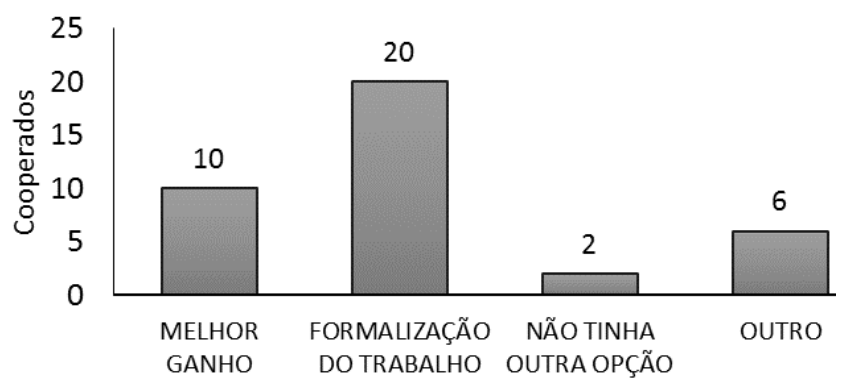

Figura 4. Razões pelas quais os entrevistados optaram em trabalhar na Cooperativa COOPERTRAGE.

Fica clara que a razão principal para o trabalhador optar pela cooperativa é a formalização do trabalho, devido possivelmente aos benefícios a que todos eles passam a ter direito. O principal deles é o recolhimento do INSS, além de receberem alimentação no local e transporte gratuito. A contribuição previdenciária dos catadores no Sul atinge apenas $25 \%$ da população (IPEA, 2013). Dentre os cooperados que apresentaram "outro" motivo por optarem por trabalhar na cooperativa, as principais razões apontadas foram proximidade da residência ou indicação por parte de algum amigo ou familiar.

Todos os entrevistados afirmaram que houve significativa mudança positiva em suas vidas após mudarem para a cooperativa. Dentre os aspectos de maior mudança, destaca-se a segurança no trabalho, pois $78 \%$ dos cooperados afirmaram que esse aspecto melhorou muito. Dentre os motivos apontados pelos entrevistados para essa melhoria com relação à segurança no trabalho, os cooperados que eram anteriormente catadores (também popularmente chamados de carrinheiros ou carroceiros) afirmaram que não utilizavam EPI's (equipamento de proteção individual), se molhavam muito com as chuvas, além de apresentarem problemas com o cavalo que puxava a carrocinha utilizada na coleta de resíduos.

Os problemas apontados envolviam situações em que o animal se recusava a andar ou estava muito lento devido entre outros fatores, a idade avançada. Os cavalos são considerados indispensáveis pelos carroceiros e são 
utilizados para diversos trabalhos além de carregar materiais recicláveis. Entretanto, tais animais são mantidos sob condições inadequadas com manejo incorreto e submetidos a falhas nutricionais significativas (GUIRRO et al., 2011). Situações desse tipo podem prejudicar tanto o animal quanto o catador, deixando-os vulneráveis a acidentes de trânsito.

Oliveira (2011), estudando a percepção de riscos ocupacionais e o perfil socioeconômico do catador de material reciclável na Bahia, observou que, para os catadores, a coleta seletiva no território público da rua tem um significado de risco, enquanto a sede da cooperativa e o trabalho em equipe representam segurança. Segundo esse autor a percepção de risco está associada à proximidade do evento para os mais expostos e é inversamente proporcional à satisfação profissional, sendo que os principais riscos reconhecidos pelos trabalhadores são os de acidentes com materiais perfurocortantes, dermatoses, exposição às substâncias em pó de alumínio, serra e vidro e levantamento manual de peso elevado.

Observa-se que os catadores de materiais recicláveis no Brasil desempenham suas atividades em condições precárias, sofrem preconceito e possuem baixo reconhecimento do papel que representam na economia e no meio ambiente (CAVALCANTE et al., 2012). Nesse contexto, em relação ao tópico de convívio com as pessoas (família, vizinhos e colegas) $81 \%$ responderam que o convívio melhorou muito e $9 \%$ responderam que não houve mudanças. Já sobre a visão da sociedade com relação à profissão, $61 \%$ dos cooperados acreditam que melhorou muito e $39 \%$ dos cooperados afirmam não ter observado mudanças, pois nunca sofreram preconceito anteriormente.

Um fator importante atrelado à identidade social do catador é a possibilidade de ser bem tratado pela população, pois se percebe que estar organizado em uma associação gera um sentimento de proteção e respeito que não existia no trabalho individual de catação (CAVALCANTE et al., 2012). Cavalcante e Franco (2007) relataram a vários riscos à saúde entre os catadores do lixão de Jangurussu em Fortaleza, Ceará, demonstrando a situação de extrema penúria em que vivem os catadores, apontando para a necessidade de se desenvolverem ações educacionais e sanitárias apropriadas ao perfil dos mesmos.

Quando a pergunta foi sobre mudanças na saúde pessoal, apenas $16 \%$ relatam que não houve mudanças, enquanto $84 \%$ afirmaram terem percebido uma grande melhora. O problema de saúde mais apontado pelos entrevistados estava relacionado à necessidade de transportar a carroça de coleta, o que ocasionava dor nas costas e pernas.

Segundo o IPEA (2013), entre os riscos a que os catadores são frequentemente submetidos estão a exposição ao calor, à umidade, os ruídos, a chuva, o risco de quedas, os atropelamentos, os cortes e a mordedura de animais, o contato com ratos e moscas, a sobrecarga de trabalho e levantamento de peso, as contaminações por materiais biológicos ou químicos etc.

De Moura (2010), que realizou pesquisa em Goiânia envolvendo 78 catadores, concluiu que as atividades eram realizadas em situações que poderiam representar riscos físicos, biológicos, químicos, ergonômicos e de acidentes e as medidas protetivas e preventivas voltadas para a saúde do catador ocorrem em pequena escala, restritas ao âmbito das cooperativas e das associações.

Com relação à renda, pode-se observar na Figura 5 um aumento no número de cooperados que recebem mais do que 1 e 2 salários mínimos. Com relação ao rendimento médio, na COOPERTRAGE a média gira em torno de mil reais (entre 1 e 2 salários mínimos) muito superior à média do Brasil e da região Sul, a qual corresponde a 596,9 reais em média (IPEA, 2013).

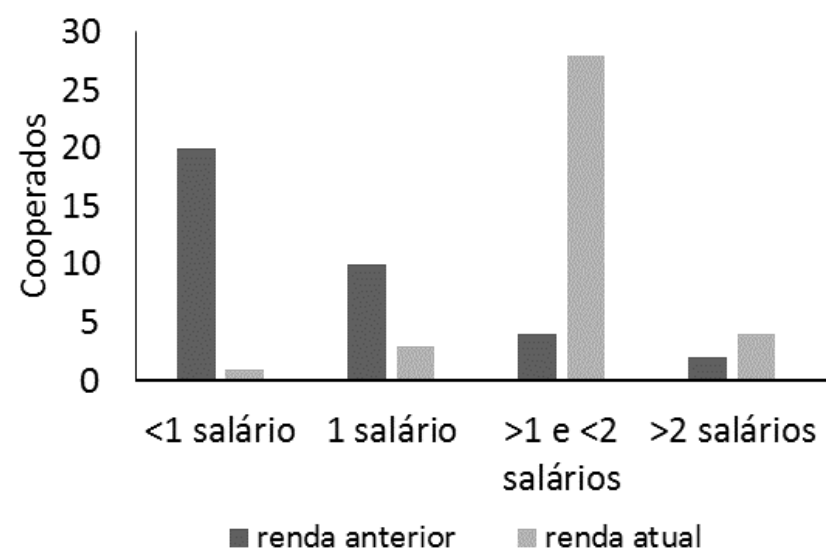

Figura 5. Média do rendimento mensal dos cooperados da COOPERTRAGE antes e após sua inserção na Cooperativa.

De Paula et al. (2010) realizaram trabalho no qual entrevistaram dois dirigentes de diferentes cooperativas de São Paulo. Uma das cooperativas possui 100 cooperados, recebe cerca de 350 toneladas mensais de resíduos e a renda gira em torno de $\mathrm{R} \$ 600$ a $\mathrm{R} \$ 800$ ao mês. A outra cooperativa tem 54 cooperados recebe 150 toneladas por mês em média e a renda mensal é de $\mathrm{R} \$$ 650 a R\$ 800. Percebe-se que a segunda cooperativa é muito similar a COOPERTRAGE em número de cooperados 
e quantidade de resíduos recebidos, entretanto, a renda da COOPERTRAGE, em média, chega a ser o dobro da obtida em São Paulo. Contudo, os trabalhos foram realizados em locais, condições e épocas distintas, o que pode influenciar nos resultados com relação aos rendimentos.

Benvindo (2010) desenvolveu um trabalho em diversas cooperativas do estado do Rio de Janeiro. A COOPCARMO situada na Baixada Fluminense é formada por 19 cooperados e grande parte destes, anterior ao ingresso na cooperativa, viviam abaixo da linha da miséria, ou seja, ganhavam menos de 1 dólar por dia. Hoje, o município é exemplo de sustentabilidade com programas de gestão de resíduos e inserção dos catadores na comunidade.

Com relação ao grau de satisfação do trabalho executado, dos 36 cooperados entrevistados, 34 afirmam estar muito satisfeitos com o trabalho executado e 2 pouco satisfeitos, nenhum afirmou estar insatisfeito. Quando a pergunta foi se os trabalhadores recomendariam a cooperativa como local de trabalho a resposta foi muito positiva. Nenhum cooperado respondeu que isso seria improvável ou pouco provável, $100 \%$ responderam que muito provavelmente recomendariam sendo que destes, 6 já o fizeram.

Carmo (2009) afirma que a ideia negativa do lixo parece colocar o catador em uma situação de desvantagem quanto à sua cidadania, pois sentem-se excluídos socialmente e com problemas na autoestima. Nesse sentido, percebe-se a influência positiva da cooperativa no resgate da identidade e dignidade desta classe trabalhadora.

Por fim, todos os entrevistados também acreditam que seu trabalho contribui muito na manutenção do meio ambiente. Assim, a cooperativa pode ser vista como elemento de prazer, transformação de vida, aceitação, crescimento e amadurecimento pessoal além da consciência ambiental dos benefícios gerados ao meio ambiente e ao desenvolvimento sustentável, e também é colocada como um mecanismo de satisfação social, profissional, de visibilidade ao trabalho e de inclusão social (OLIVEIRA, 2011).

A PNRS do Brasil preconiza o estímulo e o fortalecimento da coleta seletiva com a integração de catadores organizados, na prestação de serviço. Embora a gestão dos resíduos sólidos urbanos seja uma atribuição municipal, a PNRS estabelece mecanismos de indução deste modelo de coleta seletiva por meio da disponibilização de recursos para municípios que elaborem seus Planos de Gestão Integrada de Resíduos seguindo esta diretriz. Em 2008, a Pesquisa Nacional de Saneamento Básico apontava a existência de 994 municípios (18\% dos municípios do país) com coleta seletiva, a maioria deles $(65,7 \%)$ com catadores organizados (BESEN et al., 2014). A organização da COOPERTRAGE representa um avanço importante para a cidade de União da Vitória na gestão dos seus resíduos sólidos, atendendo às premissas da PNRS.

\section{CONCLUSÕES}

A partir do desenvolvimento deste estudo, é possível concluir que a implementação do projeto Ecocidade e da Cooperativa de Reciclagem no município de União da Vitória - PR promove mudanças positivas na gestão dos resíduos sólidos do município e nos aspectos socioeconômicos relacionados aos cooperados.

O projeto proporciona aumento expressivo no percentual de coleta de resíduos recicláveis, o que ajuda a promover a extensão da vida útil do aterro sanitário do município e a economia de recursos para confecção de novos produtos por parte das indústrias. A massa per capita de resíduos recicláveis recuperados é bastante superior à média nacional, demonstrando o avanço do município em relação à gestão municipal dos resíduos e a busca pelo atendimento a Política Nacional de Resíduos Sólidos.

Concluiu-se que a cooperativa proporciona aos cooperados melhoria em sua qualidade de vida, relacionada a aspectos como formalização do trabalho, melhores salários, melhoria na saúde e segurança no desenvolvimento da atividade. A cooperativa e os benefícios sociais que ela proporciona ao cooperado também influenciam positivamente na satisfação com o trabalho desenvolvido, no reconhecimento de sua importância e no relacionamento dos cooperados com família, amigos e sociedade em geral.

\section{AGRADECIMENTOS}

Os autores agradecem à Secretaria Municipal de Meio Ambiente de União da Vitória pelo acesso aos dados e a todos os cooperados e colaboradores da Cooperativa COOPERTRAGE por tornarem possível a realização deste estudo

\section{REFERÊNCIAS}

ABRELPE - ASSOCIAÇÃO BRASILEIRA DE EMPRESAS DE LIMPEZA PÚBLICAE RESÍDUOS ESPECIAIS. Panorama dos Resíduos Sólidos no Brasil - 2013. São Paulo, 2014. Disponível em: 
<http://www.abrelpe.org.br/Panorama/panorama2014.pdf>. Acesso em: 10/01/2017.

ALMEIDA, J. R.; ELIAS, E. T.; MAGALHÃES, M. A.; VIEIRA, A. J. D. Efeito da idade sobre a qualidade de vida e saúde dos catadores de materiais recicláveis de uma associação em Governador Valadares, Minas Gerais, Brasil. Ciência \& Saúde Coletiva, v. 14, n. 6, p. 2169-2179, 2009.

BENVINDO, A. Z. A nomeação no processo de construção do catador como ator econômico e social. 2010. 96 f. Dissertação (Mestrado em Ciências Sociais) - Universidade de Brasília, Brasília, 2010.

BESEN, G. R; RIBEIRO, H.; GÜNTHER, W. M. R.; JACOBI, P. R. Coleta seletiva na região metropolitana de São Paulo: impactos da política nacional de resíduos sólidos. Ambiente \& Sociedade, v. 17, n. 3, p. 259-278, 2014.

BRASIL. Lei no 12.305, de 2 de agosto de 2010. Institui a Política Nacional de Resíduos Sólidos; altera a Lei no 9.605, de 12 de fevereiro de 1998; e dá outras providências. Diário Oficial da União, Brasília, DF, três de agosto de 2010. Disponível em: <http://www.planalto.gov.br/ccivil 03/ ato2007-2010/2010/lei /12305.htm>. Acesso em: 23/01/2017.

BRAZ, R. F. S; BISPO, C. S.; COLOMBO, C. R.; MEDEIROS, M. F. S.; SILVA, J. C. S.; TEIXEIRA, M. T. C.; SANTHOUR, S. A.; SOUZA, M. F. Estudo sobre os aspectos sócio-econômicos dos catadores de resíduos recicláveis organizados em cooperativas na cidade de Natal - RN. Revista Eletrônica do Mestrado em Educação Ambiental, p.148-159, 2014.

CAMPOS, H. K. T. Renda e evolução da geração per capita de resíduos sólidos no Brasil, Engenharia Sanitária e Ambiental, v. 17, n. 2, p. 171-180, 2012.

CAVALCANTE, S.; FRANCO, M. F. A. Profissão perigo: percepção de risco à saúde entre os catadores do Lixão do Jangurussu. Revista Mal-Estar e Subjetividade, v. 7, n. 1, p. 211-231, 2007.

CAVALCANTE, L. P. S.; SILVA, M. C. V. G; DE ALENCAR, L. D.; VASCONCELLOS, S. C. S.; DE ASSIS, D. S. Impactos Socioambientais decorrentes da profissão catador de material reciclável. Polêmica, v. 11, n. 4, p. 1-19, 2012.

CARMO, S. A semântica do lixo e o desenvolvimento socioeconômico dos catadores de recicláveis - considerações sobre um estudo de caso múltiplo em cooperativas na cidade do Rio de Janeiro. Cadernos EBAPE.BR, Rio de Janeiro. v. 7, n. 4, p. 1-16, 2009.

COSTA, L.E.B.; COSTA, S.K.; REGO, N.A.C.; SILVA JR., M.F. Gravimétrica dos resíduos sólidos urbanos domiciliares e perfil socioeconômico no município de Salinas, Minas Gerais. Revista Ibero-Americana de Ciências Ambientais, v. 3, n. 2, p. 73-90, 2012.

DE PAULA, M. B.; DE SOUZA-PINTO, H.; DE SOUZA, M. T. S. A importância das cooperativas de reciclagem na consolidação dos canais reverso de resíduos sólidos urbanos pós-consumo. In: XIII SIMPÓSIO DE ADMINISTRAÇÃO DA PRODUÇÃO, LOGÍSTICA E OPERAÇÕES INTERNACIONAIS, 2010, São Paulo. Anais... São Paulo: FGV/EAESP, 2010. p. 1-16.
DE MOURA, A. A. S. B. F. Riscos Ambientais à Saúde Ocupacional do Catador de Recicláveis em Goiânia. 2010. $142 \mathrm{f}$. Dissertação (Mestrado em Ciência Ambiental e Saúde) Pontifícia Universidade de Goiás, Goiânia, 2010.

DEUS, R. M.; BATTISTELLE, R. A. G.; SILVA, G. H. R. Resíduos sólidos no Brasil: contexto, lacunas e tendências. Engenharia Sanitária e Ambiental, v. 20, n. 4, p. 685-698, 2015.

DIAS, D. M.; MARTINEZ, C. B.; BARROS, R. T. V.; LIBÂNIO, M. Modelo para estimativa da geração de resíduos sólidos domiciliares em centros urbanos a partir de variáveis socioeconômicas conjunturais. Engenharia Sanitária e Ambiental, v. 17, n. 3, p. 325-332, 2012.

FERREIRA SILVA, E. A.; CASTRO ALCÂNTARA, V.; PEREIRA, J. R. Governança e esfera pública sobre resíduos sólidos urbanos no âmbito municipal. Administração Pública e Gestão Social, v. 8, n. 3, p. 137-146, 2016

FREITAS, C. M. Levantamento da disposição final de resíduos sólidos urbanos em 32 municípios do Estado de Goiás. Revista Biologia Neotropical, v. 12, n. 2, p. 120-124, 2015.

FREITAS, D. G.; FERREIRA, F. P. M. Perfil dos Catadores de Materiais Recicláveis nos Lixões de Minas Gerais. Caderno de Geografia, v. 25, n. 44, p. 25-44, 2015.

GODECKE, M. V.; WALERKO, V. S. Gestão de resíduos sólidos urbanos: estudo do caso da reciclagem em Pelotas, RS. Revista Gestão \& Sustentabilidade Ambiental, v. 4, n. 1, p. $104-$ 128,2015 .

GOES, H. C. Coleta seletiva, planejamento municipal e a gestão de resíduos sólidos urbanos em Macapá/AP. Planeta Amazônia: Revista Internacional de Direito Ambiental e Políticas Públicas, n. 3, p. 45-60, 2011.

GOMES, A. P.; PANDOLFO, A.; FERRÃO, PASINI, C.; PIETTO, P. D. M.; PORTELA, N. B. Diagnóstico do sistema de gerenciamento dos resíduos sólidos urbanos do município de Passo Fundo/RS. Revista DAE, n. 190, p. 44-55, 2012.

GONÇALVES, M. A.; TANAKA, A. K.; AMENDOMAR, A. A. A destinação final dos resíduos sólidos urbanos: alternativas para a cidade de São Paulo através de casos de sucesso. Future Studies Research Journal, v. 5, n. 1, p. 96-129, 2013.

GOUVEIA, N. Resíduos sólidos urbanos: impactos socioambientais e perspectiva de manejo sustentável com inclusão social. Ciência \& Saúde Coletiva, v. 17, n. 6, p. 15031510, 2012.

GUIRRO, E. C. B. P.; HILGERT, A. R.; ENING, M. P.; LIMA, S. C.; MUNHOZ, A. P.; MARTIN, C. C.; CARVALHO, G. F.; LEMES, K. M. Extensão voltada ao cavalo e carroceiro: Projeto Carroceiro. Extensão em Foco, n. 7, p. 141-148, 2011.

HEMPE, C.; NOGUERA, J. O. C. A educação ambiental e os resíduos sólidos urbanos. Revista Eletrônica em Gestão, Educação e Tecnologia Ambiental, n. 5, p. 682-695, 2012.

IBGE - INSTITUTO BRASILEIRO DE GEOGRAFIA E ESTATÍSTICA. Censo Demográfico 2010. Ministério do Planejamento, 
Orçamento e Gestão. Instituto Brasileiro de Geografia e Estatística - IBGE. Rio De Janeiro, 2010. Disponível em: <http://www.ibge.gov.br/home/estatistica/populacao/censo201 o/>. Acesso em: 20/01/2017.

IPEA - INSTITUTO DE PESQUISA ECONÔMICA APLICADA. Situação Social das Catadoras e dos Catadores de Material Reciclável e Reutilizável. Brasília, 2013. Disponível em: $<$ http://www.ipea.gov.br/agencia/images/stories/PDFs/situacao social/131219 relatorio situacaosocial mat reciclavel brasil.p df>. Acesso em: 20/01/2017.

JACOBI, P. R.; BESEN, G. R. Solid waste management in São Paulo: the challenges of sustainability. Estudos Avançados, v. 25, n. 71, p. 135-158, 2011.

JESUS, M. C. P.; SANTOS, S. M. R.; ABDALLA, J. G. F.; JESUS, P. B. R.; ALVES, M. J. M.; TEIXEIRA, N.; JESUS, R. R.; VILELA, M. M. P.; MATTOS, L. R. Avaliação da qualidade de vida de catadores de materiais recicláveis. Revista Eletrônica de Enfermagem, v. 14, n. 2, p. 277-85.

LINHARES MAIA, H. K.; ALENCAR, L.D.; BARBOSA, E.M.; BARBOSA, M.F.N. Política nacional de resíduos sólidos: um marco na legislação ambiental brasileira. Polêmica, v. 13, n. 1, p. 1-7, 2014.

MINISTÉRIO DAS CIDADES; SECRETARIA NACIONAL DE SANEAMENTO AMBIENTAL. Sistema Nacional de Informações sobre Saneamento - SNIS: Diagnóstico do manejo de resíduos sólidos urbanos - 2013. Brasília: MCIDADES. SNSA, 2015. Disponível em: <http://www.snis.gov.br/diagnostico-residuossolidos>. Acesso em: 20/01/2017.

OLIVEIRA, D. A. M. Percepção de riscos ocupacionais em catadores de materiais recicláveis: estudo em uma cooperativa em Salvador-Bahia. 2011. 175 f. Dissertação (Mestrado em Saúde, Ambiente e Trabalho) - Universidade Federal da Bahia, Salvador, 2011.

PINHEL, J. R. (Org.). Do lixo à cidadania: guia para a formação de cooperativas de catadores de materiais recicláveis. São Paulo: Peirópolis, 2013. 242 p.

PREFEITURA MUNICIPAL DE UNIÃO DA VITÓRIA. Dados gerais. Disponível em: <http://www.pmuniaodavitoria.com.br/index . php?option $=$ com content \&view=article\&id=11\&ltemid=21>. Acesso em: 15/05/2015.

RAMOS, R. R. Gestão de resíduos sólidos urbanos: indicadores de sustentabilidade aplicados a programas de gestão e associações de catadores de materiais recicláveis. Geografia, v. 22, n. 3. p. 27-45, 2013.

SIQUEIRA, M. M.; SOARES, M. S. Saúde coletiva, resíduos sólidos urbanos e os catadores de lixo. Ciência \& Saúde Coletiva, v. 14, n. 6, p.2115-2122, 2009.

SOBARZO, L. C. D.; MARIN, F. A. D. G. Resíduos sólidos: representações, conceitos e metodologias: propostas de trabalho para o ensino fundamental. Revista de Ensino de Geografia, v. 1, n. 1, p. 3-14, 2010.

TEIXEIRA, K. M. D. Trabalho e perspectivas na percepção de catadores de materiais recicláveis. Psicologia \& Sociedade, v. 27, n. 1, p. 98-105, 2015. 